\title{
Protective effect of diet supplemented with rice prolamin extract against DNCB-induced atopic dermatitis in BALB/C mice
}

\author{
Hyun-Joong Yoon ${ }^{1 \dagger}$, Mi-Sun Jang ${ }^{1 \dagger}$, Hyun-Woo Kim², Dong-Up Song ${ }^{1}$, Kwang-Il Nam ${ }^{1}$ Choon-Sang Bae , \\ Seong-Jin Kim', Seung-Rock Lee ${ }^{1}$, Chang-Sub Ku³, Dong-II Jang ${ }^{3}$ and Bong-Whan Ahn ${ }^{\text {** }}$
}

\begin{abstract}
Background: Rice prolamin has been reported to possess antioxidative, anti-inflammatory and immune-promoting properties. This study is aimed to examine the protective effects of dietary rice prolamin extract (RPE) against dinitrochlorobenzene (DNCB)-induced atopic dermatitis (AD)-like skin lesions in mice.

Methods: BALB/c mice were fed diet supplemented with 0-0.1 \% RPE for 6 weeks. For the last 2 weeks, $1 \%$ or $0.2 \%$ DNCB was applied repeatedly to the back skin of mice to induce AD-like lesions. Following AD induction, the severity of skin lesions was examined macroscopically and histologically. In addition, the serum levels of IgE, lgG1 and IgG2a were determined by ELISA, and the mRNA expression of IL-4 and IFN- $\gamma$ in the skin was determined by real-time PCR.

Results: Dietary RPE suppressed the clinical symptoms of DNCB-induced dermatitis as well as its associated histopathological changes such as epidermal hyperplasia and infiltration of mast cells and eosinophils in the dermis. RPE treatment also suppressed the DNCB-induced increase in transepidermal water loss. Dietary RPE inhibited the DNCB-induced enhancement of serum IgE and IgG1 levels, whereas it increased the serum lgG2a level in DNCB-treated mice. In addition, dietary RPE upregulated the IFN- $\gamma$ mRNA expression and downregulated the IL-4 mRNA expression in the skin of DNCB-treated mice.
\end{abstract}

Conclusions: The above results suggest that dietary RPE exerts a protective effect against DNCB-induced AD in mice via upregulation of Th1 immunity and that RPE may be useful for the treatment of AD.

Keywords: Dietary rice prolamin extract, Atopic dermatitis, Interferon-gamma

\section{Background}

$\mathrm{AD}$ is a chronic inflammatory skin disease that often begins in infancy. It causes enormous physical discomfort and imposes huge demands on time and resources [1]. $\mathrm{AD}$ is characterized by pruritus and eczematous skin lesions, elevated serum immunoglobulin (Ig) E level, and infiltration of immune cells such as mast cells, eosinophils and lymphocytes in the skin $[2,3]$. Th2 cells play a key role in the pathogenesis of $\mathrm{AD}[4,5]$. They synthesize high levels of IL-4 and other Th2 cytokines, which lead to immunoglobulinemia E, eosinophilia,

\footnotetext{
* Correspondence: bwahn@jnu.ac.kr

${ }^{\dagger}$ Equal contributors

'Chonnam University Research Institute of Medical Sciences, Chonnam National University, Gwangju, South Korea

Full list of author information is available at the end of the article
}

epidermal thickening and other AD-associated inflammatory changes. Conversely, Th1 cells suppress the Th2 immune responses through production of IFN- $\gamma$ [6]. Therefore, promotion of Th1 immunity and suppression of Th2 immunity can be an effective therapeutic measure for $\mathrm{AD}[6,7]$. In fact, some strains of probiotic bacteria have been reported to exert beneficial effects in AD by promoting IFN- $\gamma$ production [8-11].

Rice is a staple food worldwide [12]. In addition, rice has been described to have various pharmacological and biological activities including hypocholesterolemic and anticarcinogenic effects [13-20]. Rice proteins are nutritious for humans with hypoallergenic properties among the cereal proteins. They consist of four important fractions, identified by differential solubility: water-soluble albumin, salt-soluble globulin, alkali-soluble glutelin and 
alcohol-soluble prolamin [12, 21]. Recently, antioxidative [22], anti-inflammatory [23] and immune-promoting [24] activities of rice prolamin have been reported. According to Chen et al. and other investigators [24, 25], human peripheral blood mononuclear cells (HPBMCs) exposed to rice prolamin secreted IFN- $\gamma$, and the conditioned medium prepared from HPBMCs cultured in the presence of rice prolamin inhibited the growth of human leukemia U937cells and triggered the differentiation of the cells toward monocytes. Because rice prolamin is indigestible $[12,26]$, an exception among the rice proteins, dietary rice prolamin seems to pass through the intestine in macromolecular forms, where it may induce immune reactions. Therefore, the above observations suggest that dietary rice prolamin may be beneficial for AD via immunomodulatory function.

In the present study, we examined the protective effects of dietary supplementation of rice prolamin extract (RPE) on DNCB-induced AD-like lesions in BALB/c mice. We also examined the effects of dietary RPE on Th1 and Th2 immunities in the above mice.

\section{Methods}

\section{Animals and materials}

Six-week-old female BALB/c mice were purchased from Jungang Lab Animal, Inc. (Seoul, Korea) and were housed in an air-conditioned room $\left(22 \pm 2{ }^{\circ} \mathrm{C}\right)$ with a 12-h darklight cycle and were allowed free access to water and food. 2, 4-Dinitrochlorobenzene (DNCB) was purchased from Sigma-Aldrich Co. (St. Louis, MO, USA) and dissolved in acetone-olive oil $(4: 1, \mathrm{v} / \mathrm{v})$. All other reagents used were of the analytical grade commercially available. This study was approved by the Institutional Animal Care and Use Committee of Chonnam National University Medical School (approval No.: CNU IACUC-H-2015-5).

\section{Preparation and feeding of rice prolamin extract (RPE)}

Rice (cultivar Dongjinchal) supplied from Changpyeong $\mathrm{NH}$ (Damyang, Korea) was ground to pass through a $0.18 \mathrm{~mm}$ screen (Daehwa Precesion, Cheonan, Korea). Prolamins were extracted from rice flour with $70 \%$ ethanol, as described previously [27] with minor modifications. Rice flour $(100 \mathrm{~g})$ was defatted with hexane and dried in a fume hood at room temperature for $24 \mathrm{~h}$. The defatted flour was then extracted by stirring in $400 \mathrm{ml}$ of $5 \% \mathrm{NaCl}$ at $20{ }^{\circ} \mathrm{C}$ for $4 \mathrm{~h}$ and centrifuged at $3,000 \times \mathrm{g}$ for $30 \mathrm{~min}$ to remove the albumin and globulin fractions. The residue after extraction of albumin-globulin was extracted with $300 \mathrm{ml}$ of $70 \%$ ethanol at $20{ }^{\circ} \mathrm{C}$ for $4 \mathrm{~h}$ to isolate the prolamin fraction. Each extraction step was repeated twice to remove most of the protein fraction. The prolamin fraction was then dialyzed against distilled water, lyophilized and then stored at $4{ }^{\circ} \mathrm{C}$. An aliquot of the freeze-dried extract was dissolved in $70 \%$ ethanol containing $25 \mathrm{mM} \mathrm{NaOH}$ and its protein concentration was determined with a BCA protein assay kit (Thermo Scientific, Rockford, IL, USA) and purified $13 \mathrm{kDa}$ prolamin as the standard. The average total solids in the prolamin fraction extracted from $100 \mathrm{~g}$ rice flour were $0.53 \mathrm{~g}$ and the average protein content of the solids was $64.5 \%$. The mice were fed a dietary powder supplemented with $0,0.05 \%$ and $0.1 \%$ lyophilized RPE. The dietary powder was prepared by pulverizing the standard laboratory chow R03 (SAFE Lab Diets, Augy, France), and fresh diet was provided daily for 6 weeks according to the schedule summarized in Fig. 1.

\section{Induction of AD-like lesions}

The DNCB patched model described by Lee et al. [28] was used. The backs of mice were shaved with an electric clipper and depilatory cream a day before DNCB sensitization. The DNCB sensitization and challenge were performed for 2 weeks according to the schedule summarized in Fig. 1. For the sensitization process, a $1 \mathrm{~cm}^{2}$ gauze-attached patch (Tegaderm, $3 \mathrm{M}$ Health Care, St. Paul, MN, USA) was applied with $0.1 \mathrm{ml}$ of $1 \%$ DNCB and attached to the shaved area for 2 days on day 0 and 3 . For the challenge process, the gauze-attached patch was applied with $0.1 \mathrm{ml}$ of $0.2 \% \mathrm{DNCB}$ and attached to the sensitized area for a day on day 7 and 10 . The mice were sacrificed on day 14 to evaluate the effects of DNCB and RPE treatments.

\section{Assessment of the severity of skin lesions}

The severity of DNCB-induced skin lesions was clinically assessed as previously described $[29,30]$. The dermatitis score was defined as a sum of individual scores $(0$, no symptom; 1 , mild; 2 , moderate; 3 , severe) for the following four signs and symptoms: erythema/hemorrhage, edema, erosion and dryness.

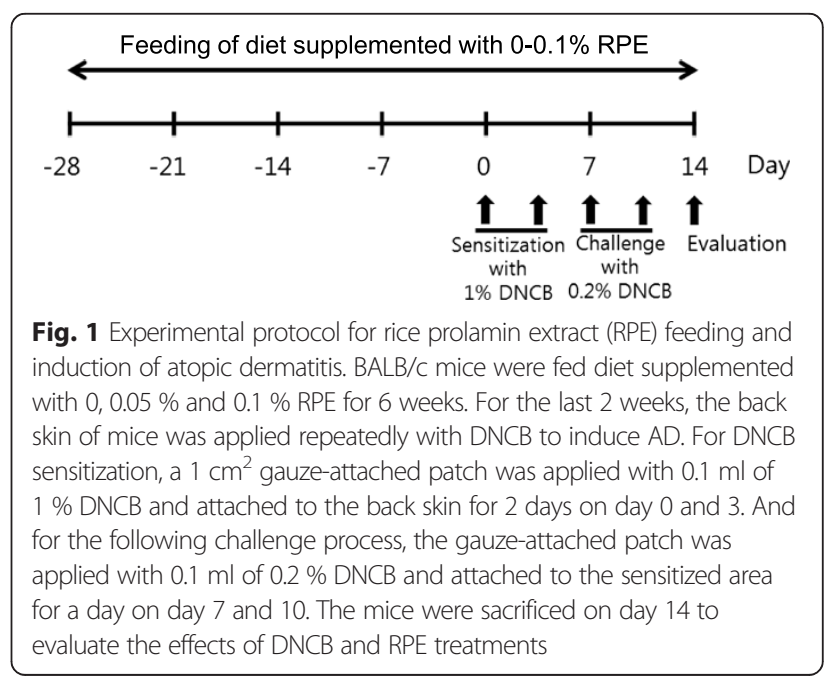




\section{Measurement of transepidermal water loss (TEWL)}

TEWL was measured under forane anesthesia using a Tewameter TM300 (Courage and Khazaka Electronic $\mathrm{GmbH}$, Köln, Germany) in a climate-controlled room.

\section{Histopathological analysis}

The dorsal skins of the mice were removed and fixed in $10 \%$ phosphate-buffered formalin. The skin sections ( $4 \mu \mathrm{m}$ thick) were stained with hematoxylin and eosin to evaluate the epidermal hyperplasia and the other sections were stained with toluidine blue and Giemsa to evaluate the infiltration of mast cells and eosinophils.

\section{Measurement of serum immunoglobulins}

Blood samples were collected by cardiac puncture under anesthesia, and sera were collected by centrifugation and stored at $-80{ }^{\circ} \mathrm{C}$ until use. The serum IgE, IgG1 and IgG2a levels were measured with monoclonal antibody pairs by sandwich ELISA using commercial kits (eBioscience, San Diego, CA, USA). Briefly, microtiter plates were coated with monoclonal rat antimouse IgE, IgG1 or IgG2a antibody, followed by sequential incubation of serially diluted purified mouse IgE, IgG1 and IgG2a (standards) or sera (in triplicate), horseradish peroxidase-conjugated monoclonal antimouse IgE, IgG1 or IgG2a antibody, and then the substrate. The absorbance of the resulting product was read using a microplate reader (BioTek Instruments, Inc., Winooski, VT, USA).

\section{Measurement of IL-4 and IFN- $\gamma$ mRNA expression in the} skin by real-time polymerase chain reaction (RT-PCR)

Total RNA was extracted from skin tissue with the TRIzol reagent (Invitrogen Life Technologies, Grand Island, NY, USA) according to the manufacturer's instruction. The quantity and purity of total RNA were determined with a Nanodrop reader (Nanodrop Technologies, Wilmington,
DE, USA). One microgram of total RNA was converted to the first-strand DNA with Moloney murine leukemia virus (MMLV) reverse transcriptase (Invitrogen Life Technologies) and RNAsin (Takara, Otsu, Shiga, Japan). cDNA was amplified using gene-specific primers and GoTaq $^{\oplus}$ DNA polymerase (Promega, Madison, WI, USA). Primer sequences were as follows: IFN- $\gamma, 5^{\prime}$-GTCAACAACCCACAGGTCCA-3'/5' -ACTCCTTTTCCGCT TCCTGA-3'; IL-4, 5' - CTTCCAAGGTGCTTCGCAT A-3'/5'-AAGCCCGAAAGAGTCTCTGC-3'; $\beta$-Actin, 5' - CTAGGCACCAGGGTGTGATG-3'/5' -GGGGTA CTTCAGGGTCAGGA-3'. $\beta$-Actin was used as the internal control.

\section{Statistical analysis}

The results are presented as mean $\pm \mathrm{SD}$. The significance of differences of all results was analyzed by one-way analysis of variance (ANOVA) followed by the Scheffe's test.

\section{Results}

Effect of dietary RPE on clinical symptoms of DNCBinduced dermatitis in BALB/c mice

Following repeated application of DNCB to the back skin of mice for 2 weeks, AD-like lesions developed. Clinical symptoms such as erythema/hemorrhage, edema, erosion and dryness were evident with the average dermatitis score approaching 10 (Fig. 2). Skin barrier function also decreased markedly in DNCB-treated mice compared to the normal group, as evidenced by the increase in TEWL (Fig. 3). Dietary RPE dose-dependently suppressed the clinical symptoms of dermatitis and attenuation of skin barrier function induced by DNCB treatment. It inhibited the DNCB-induced increase in dermatitis score by 40.7 and $68.4 \%$ at 0.05 and $0.1 \%$, respectively, and inhibited the DNCB-induced TEWL increase by 38.2 and $59.7 \%$ at 0.05 and $0.1 \%$, respectively (Figs. 2 and 3 ).
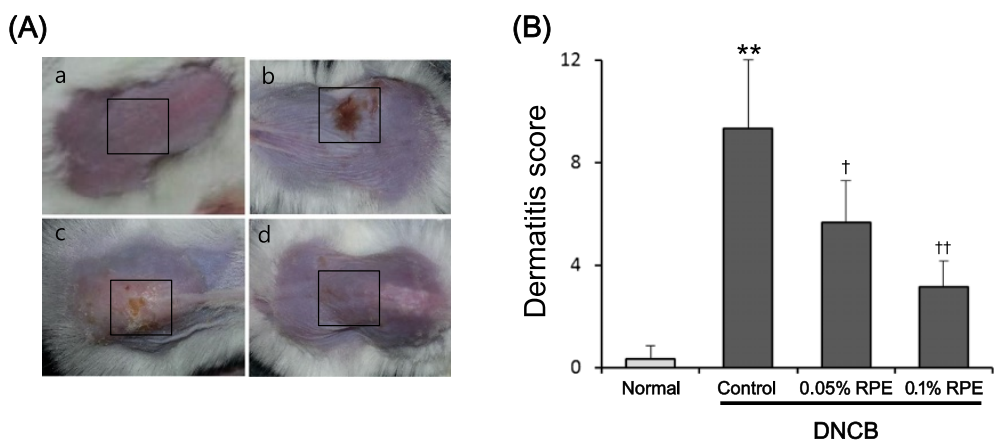

Fig. 2 The preventive effect of dietary RPE on AD-like skin lesions induced by DNCB treatment in mice. a Photographs showing skin lesions (marked with a square) in the different groups of experimental mice: a, normal control; b, DNCB control; c, DNCB + $0.05 \%$ RPE; $d$, DNCB + 0.1 \% RPE. $\mathbf{b}$ The severity of clinical symptoms of the skin lesions was evaluated macroscopically and expressed as the dermatitis score (maximum score, 12) which was defined as a sum of individual scores (0, no symptom; 1 , mild; 2 , moderate; 3 , severe) for the following four symptoms: erythema/ hemorrhage, edema, erosion and dryness. ${ }^{* *} P<0.01$ compared with the normal group, and ${ }^{\dagger} P<0.05$, ${ }^{+\dagger} P<0.01$ compared with the DNCB control group $(n=6)$ 


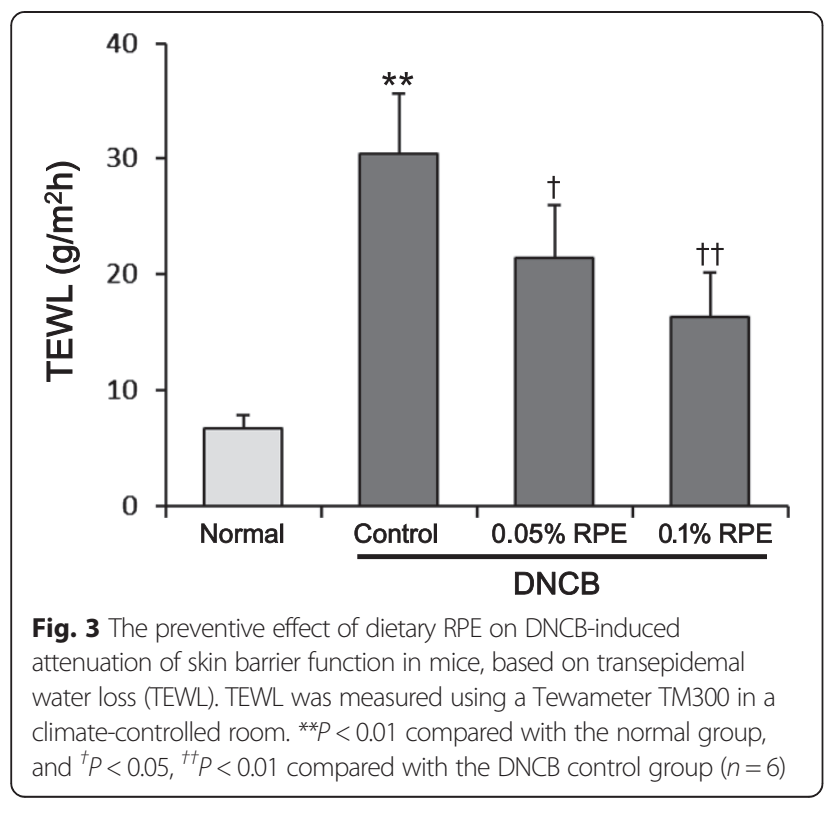

\section{Histopathological changes in the skin caused by DNCB and RPE treatments}

We examined the histopathological changes in the back skins of experimental mice (Fig. 4). The skins of the DNCB-treated group showed markedly epidermal hyperplasia as compared to the normal group. Intriguingly, this hyperplasia was significantly reduced by RPE treatment (Fig. 4a, b). As seen in toluidine blue and Giemsa stains, the number of mast cells and eosinophils in the dermis of DNCB-treated mice was markedly increased as compared to the normal group. In addition, these DNCB-induced increments of inflammatory cells were significantly suppressed by RPE treatment (Fig. 4a, c, d).

\section{Changes in the serum concentrations of $\lg E$, $\lg G 1$ and IgG2a caused by DNCB and RPE treatments}

Because serum IgE levels are correlated with the severity of $\mathrm{AD}$ and the serum levels of IgE, IgG1 and IgG2a are associated with Th2 or Th1 immunity [1,31], we examined the serum levels of these three Igs in mice to evaluate the effects of DNCB and RPE on systemic Th1 and Th2 immunities (Table 1). The serum levels of IgE and IgG1 were markedly increased in the DNCB-treated group, although the serum IgG2a level was not changed significantly by this treatment. Dietary RPE influenced the serum Ig levels differently in DNCB-treated mice. It dose-dependently reduced the serum levels of IgE and IgG1, whereas $0.1 \%$ RPE significantly increased the serum IgG2a level in DNCB-treated mice.

\section{DNCB and RPE treatments change the mRNA expression of IL-4 and IFN- $\gamma$ in the skin}

To evaluate the effects of DNCB and RPE treatments on skin Th1 and Th2 immunities, we examined the expression of IL- 4 and IFN- $\gamma$ mRNAs in the back skins of experimental mice. As shown in Fig. 5, the IL-4 mRNA expression was markedly increased by DNCB treatment, whereas, the IFN- $\gamma$ mRNA expression was significantly decreased in DNCB-treated mice as compared to the normal group. These results are consistent with earlier observations [28]. Dietary RPE reversed these DNCB-induced changes in Th1 and Th2 cytokine mRNA expressions. That is, RPE treatment suppressed the DNCB-induced increase of IL-4 mRNA expression (Fig. 5a), whereas it increased the IFN- $\gamma$ mRNA expression up to more than twice the level of the DNCB control group (Fig. 5b).

\section{Discussion}

This study showed that dietary RPE supplementation inhibited the AD-like pathology induced by DNCB treatment in BALB/c mice. RPE treatment suppressed not only the clinical symptoms of dermatitis such as erythema, edema, erosion and dryness (Fig. 2), but also its histopathological changes such as epidermal hyperplasia and infiltration of mast cells and eosinophils in the dermis (Fig. 4). In addition, RPE treatment suppressed the DNCB-induced attenuation of skin barrier function, as evidenced by the changes in TEWL (Fig. 3). The immune cells infiltrated in the skin tissue, following antigen binding, become activated and secrete a variety of bioactive chemical mediators including histamine, proteases, eicosanoids, cytokines and chemokines, and proinflammatory proteins [32]. Bioactive mediators can cause locally and systemically diverse symptoms and signs including those observed in Figs. 2, 3, and 4 [32]. Therefore, our results indicate that dietary RPE may effectively prevent $\mathrm{AD}$ symptoms.

As shown in Table 1, dietary RPE reduced the serum levels of IgE and IgG1, whereas it raised the serum IgG2a level, in DNCB-treated mice. It is known that IFN- $\gamma$ stimulates the expression of IgG2a and inhibits the production of IgE and IgG1. In contrast, IL-4 has powerful effect in stimulating the expression of $\operatorname{IgE}$ and IgG1 but markedly inhibits the expression of IgG2a [31]. Although the mechanism for the anti-AD action of RPE remains unclear, the results of Table 1 strongly suggest that upregulation of Th1 immunity and downregulation of Th2 immunity are a principal mechanism for the RPE action. Indeed, we found that RPE treatment suppressed IL-4 mRNA expression and raised IFN- $\gamma$ mRNA expression in the skin of DNCB-treated mice (Fig. 5), supporting the above suggestion that upregulation of Th1 immunity and downregulation of Th2 immunity are involved in the anti-AD action mechanism of dietary RPE. Because Th2 cytokine production is a default pathway in many systems [33-35] and Th1 and Th2 expressions are antagonistic to each other, it follows that upregulation of IFN- $\gamma$ expression by RPE may be the primary causative 


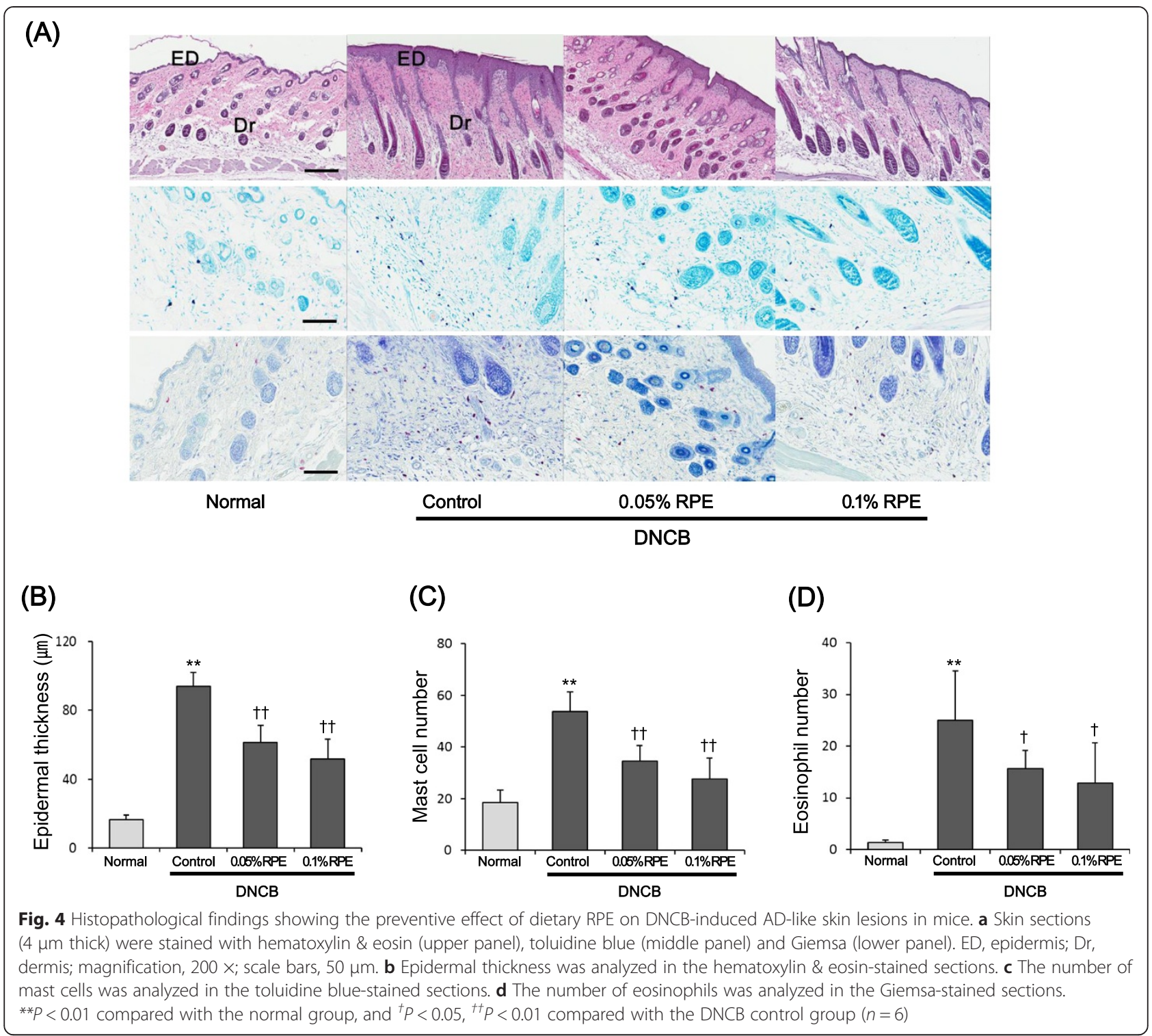

factor that leads to downregulation of Th2 expression and other RPE effects observed in this study. For example, IFN- $\gamma$ can seriously influence Th1/Th2 cell differentiation and cytokine production [36]. IFN- $\gamma$ activates signal transducer and activator of transcription 1 (Stat1),

Table 1 Effects of dietary RPE on serum levels of $\operatorname{lgE}$, IgG1 and IgG2a in DNCB-treated mice

\begin{tabular}{lcll}
\hline Treatment & $\operatorname{lgE}(\mathrm{ng} / \mathrm{ml})$ & $\operatorname{lgG} 1(\mathrm{mg} / \mathrm{ml})$ & $\operatorname{lgG} 2 \mathrm{a}(\mathrm{mg} / \mathrm{ml})$ \\
\hline Normal & $42.7 \pm 14.6$ & $0.334 \pm 0.041$ & $0.102 \pm 0.019$ \\
DNCB & $264.0 \pm 38.5^{* *}$ & $2.326 \pm 0.411^{* *}$ & $0.110 \pm 0.013$ \\
DNCB + 0.05\% RPE & $175.0 \pm 26.9^{\dagger \dagger}$ & $1.648 \pm 0.274^{\dagger+}$ & $0.124 \pm 0.024$ \\
DNCB + 0.1 \% RPE & $148.7 \pm 25.4^{+\dagger}$ & $1.388 \pm 0.216^{\dagger \dagger}$ & $0.159 \pm 0.016^{\dagger}$ \\
\hline
\end{tabular}

The serum Ig levels were determined by ELISA. ${ }^{*} P<0.01$ compared with the normal group, and ${ }^{+} P<0.05,{ }^{t+} P<0.01$ compared with the DNCB control group $(n=6)$ which upregulates the leading Th1 transcription factor, T-bet, further enhancing Th1 cytokine production. Concurrently, IFN- $\gamma$ inhibits Th2 cytokine production by interfering with GATA, a Th2 transcription factor. Furthermore, inflammatory cells in local skin lesions are recruited by complex interactions of chemokines and chemokine receptors whose expression is also regulated by Th1 and Th2 cytokines [32, 37]. IFN- $\gamma$ amplifies Th1 responses by inducing Th1-type chemokines and their receptors and by preventing the expression of Th2-type receptor ligands. $\mathrm{AD}$ is characterized by hyperactivated Th2 cytokines that lead to immunoglobulinemia E, eosinophilia, epidermal thickening and other $\mathrm{AD}$-associated inflammatory changes $[4,5]$. These Th2 immune responses, however, can be suppressed by IFN- $\gamma$ [6]. The formation and maintenance of skin barrier are also influenced by Th1 
(A)

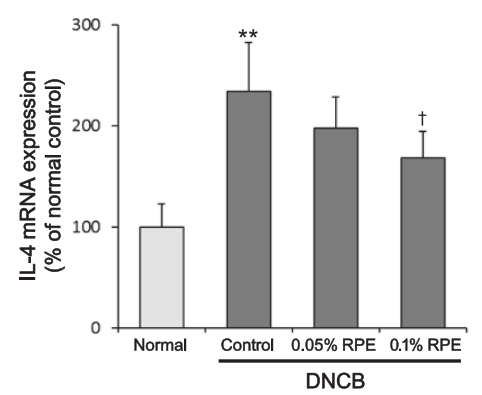

(B)

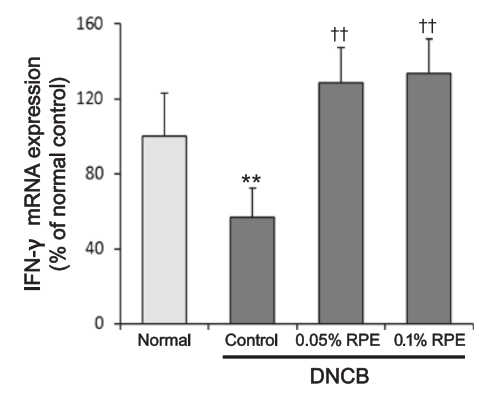

Fig. 5 Effects of dietary RPE on mRNA expression of IL-4 (a) and IFN-y (b) in the skin of DNCB-treated mice. The cytokine mRNA expressions were determined by real-time PCR. ${ }^{*} P<0.01$ compared with the normal group, and ${ }^{+} P<0.05,{ }^{t \dagger} P<0.01$ compared with the DNCB control group $(n=6)$

and Th2 cytokines [38]. IFN- $\gamma$ stimulates ceramide synthesis through the action of enzymes, sphingomyelinase and glucocebrosidase, resulting in suppression of TEWL $[38,39]$. And IFN- $\gamma$ may play a role in maintaining the skin barrier by regulating Th2 cytokine receptors, because Th2 cytokines inhibit the formation of skin barrier [38]. Thus, IFN- $\gamma$ can modify all the DNCB-induced AD-like changes observed in this study: clinical symptoms, attenuation of skin barrier function, immune cell infiltration, and changes in serum IgE, IgG1 and IgG2a levels and skin Th1 and Th2 cytokine mRNA expressions.

Although earlier studies showed that PBMCs exposed to rice prolamin secreted IFN- $\gamma$ in vitro $[27,28]$, it is uncertain how dietary RPE can activate Th1 responses in vivo. As dendritic cells are the only antigen presenting cells known to sample luminal contents from the intestine $[35,40]$, they play a critical role in Th1 cell activation by commensal bacteria- and food-associated antigens [35]. They sample and uptake antigens from the gastrointestinal luminal compartment and processed the antigens [40-42]. After migrating to nearby lymph nodes, they present the processed antigens to $\mathrm{T}$ cells and stimulate $\mathrm{T}$ cell differentiation. They also secrete IL-12, which binds to the IL-12 receptor on T cells and signals to activate Th1 cell differentiation [36]. The differentiated Th1 cells can then migrate to extraintestinal sites [35]. It will be an important task to find out whether dietary RPE acts in a similar way to the above mentioned antigens or if it acts by other mechanisms.

In the present study, dietary RPE significantly prevented the AD-like symptoms induced by $\mathrm{DNCB}$ treatment in mice and it improved the Th1/Th2 balance that was skewed to Th2 by DNCB treatment. Because rice is a common, stable and safe food, RPE can be a potential resource for the development of new therapeutic agents for AD. Further studies including clinical researches are required to prove this possibility.

\section{Conclusions}

This study indicated that dietary RPE was protective against DNCB-induced AD-like lesions in BALB/c mice. Our results suggest that dietary RPE exerts its anti-AD effect via upregulation of Th1 immunity and that RPE may be useful for the treatment of AD.

\section{Competing interests}

The authors declare that they have no competing interests.

\section{Authors' contributions}

HJY, MSJ and HWK designed and carried out the experiments. KIN and CSB performed the histopathological analyses. DUS and BWA analyzed data. SJK, CSK and DIJ contributed reagents/materials/analysis tools. SJK and SRL supervised and corrected the manuscript. BWA designed the study and wrote the manuscript. All authors read and approved the final manuscript.

Authors' information

Not applicable.

\section{Acknowledgements}

This study was supported by a grant of the Korean Health Technology R\&D Project, Ministry of Health \& Welfare, Republic of Korea. (Grant No.: HN11C0047).

\section{Author details}

${ }^{1}$ Chonnam University Research Institute of Medical Sciences, Chonnam National University, Gwangju, South Korea. ${ }^{2}$ Research Center for Oral Disease Regulation of the Aged (MRC), College of Dentistry, Chosun University, Gwangju, South Korea. ${ }^{3}$ COTDE Inc. 19-3, Ugakgol-gil, Susin-myeon, Cheonan-si, Chungcheongnam-do 330-882, South Korea.

Received: 23 April 2015 Accepted: 2 October 2015

Published online: 14 October 2015

\section{References}

1. Weston S, Halbert A, Richmond P, Prescott SL. Effects of probiotics on atopic dermatitis: a randomised controlled trial. Arch Dis Child. 2005;90(9):892-7.

2. Bogfuniewicz M, Schmid-Grendelmeier P, Leung DY. Atopic dermatitis. J Allergy Clin Immunol. 2006;118(1):40-3.

3. Liu FT, Goodarzi H, Chen HY. IgE, mast cells, and eosinophils in atopic dermatitis. Clin Rev Allergy Immunol. 2011;41(3):298-310.

4. Chan LS, Robinson N, Xu L. Expression of interleukin-4 in the epidermis of transgenic mice results in a pruritic inflammatory skin disease: an experimental animal model to study atopic dermatitis. J Invest Dermatol. 2001;117(4):977-83. 
5. Brandt EB, Sivaprasad U. Th2 cytokines and atopic dermatitis. J Clin Cell Immunol. 2011;2(3):110.

6. Hattori K, Nishikawa M, Watcharanurak K, Ikoma A, Kabashima K, Toyota H, et al. Sustained exogenous expression of therapeutic levels of IFN-gamma ameliorates atopic dermatitis in NC/Nga mice via Th1 polarization. J Immunol. 2010;184(5):2729-35.

7. Won TJ, Kim B, Lim YT, Song DS, Park SY, Park ES, et al. Oral administration of Lactobacillus strains from Kimchi inhibits atopic dermatitis in NC/Nga mice. J Appl Microbiol. 2011;110(5):1195-202.

8. Özdemir Ö. The role of probiotics in atopic dermatitis prevention and therapy. In: Esparza-Gordillo J, Dekio I, editors. Atopic Dermatitis - Disease Etiology and Clinical Management. Rijeka: Intech; 2012. p. 353-86.

9. West $\mathrm{CE}$, Hammarström ML, Hernell O. Probiotics during weaning reduce the incidence of eczema. Pediatr Allergy Immunol. 2009;20(5):430-7.

10. Sistek D, Kelly R, Wickens $K$, Stanley T, Fitzharris P, Crane J. Is the effect of probiotics on atopic dermatitis confined to food sensitized children? Clin Exp Allergy. 2006;36(5):629-33.

11. Pohjavuori $\mathrm{E}$, Viljanen $\mathrm{M}$, Korpela $\mathrm{R}$, Kuitunen $\mathrm{M}$, Tiittanen $\mathrm{M}$, Vaarala $\mathrm{O}$, et al. Lactobacillus GG effect in increasing IFN-gamma production in infants with cow's milk allergy. J Allergy Clin Immunol. 2004;114(1):131-6.

12. Juliano BO. RICE Chemistry and Technology. 2nd ed. Minnesota: The American Association of Cereal Chemists; 1985.

13. Qureshi AA, Sami SA, Salser WA, Khan FA. Dose-dependent suppression of serum cholesterol by tocotrienol-rich fraction (TRF25) of rice bran in hypercholesterolemic humans. Atherosclerosis. 2002;161(1):199-207.

14. Yang L, Kumagai $T$, Kawamura H, Watanabe T, Kubota M, Fujimura S, et al. Effects of rice proteins from two cultivars, Koshihikari and Shunyo, on cholesterol and triglyceride metabolism in growing and adult rats. Biosci Biotechnol Biochem. 2007;71(3):694-703.

15. Katayama M, Sugie S, Yoshimi N, Yamada Y, Sakata K, Qiao Z, et al. Preventive effect of fermented brown rice and rice bran on diethylnitrosoamine and phenobarbital-induced hepatocarcinogenesis in male F344 rats. Oncol Rep. 2003;10(4):875-80.

16. Shibata T, Nagayasu H, Kitajo H, Arisue M, Yamashita T, Hatakeyama D, et al. Inhibitory effects of fermented brown rice and rice bran on the development of acute hepatitis in Long-Evans Cinnamon rats. Oncol Rep. 2006;15(4):869-74.

17. Yamazaki K, Murray JA, Kita $H$. Innate immunomodulatory effects of cereal grains through induction of IL-10. J Allergy Clin Immunol. 2008;121(1):172-8

18. Islam MS, Murata T, Fujisawa M, Nagasaka R, Ushio H, Bari AM, et al. Anti-inflammatory effects of phytosteryl ferulates in colitis induced by dextran sulphate sodium in mice. Br J Pharmacol. 2008;154(4):812-24.

19. Murakami M, Ota H, Sugiyama A, Ishizone S, Maruta F, Akita N, et al. Suppressive effect of rice extract on Helicobacter pylori infection in a Mongolian gerbil model. J Gastroenterol. 2005;40(5):459-66.

20. Song DU, Jang MS, Kim HW, Yoon HJ, Chay KO, Joo YE, et al. Gastroprotective effects of glutinous rice extract against ethanol-, indomethacin-, and stress-induced ulcers in rats. Chonnam Med J. 2014;50(1):6-14

21. Shewry PR, Halford NG. Cereal seed storage proteins: structures, properties and role in grain utilization. J Exp Bot. 2002:53(370):947-58.

22. Kawase SI, Matsumura Y, Murakami H, Mori T. Comparison of antioxidative activity among three types of prolamin subunits. J Cereal Sci. 1998;28(1):33-41.

23. Chung CY, Park YL, Kim N, Oh HH, Myung DS, Kim JS, et al. Rice prolamin extract ameliorates acute murine colitis by inhibiting nuclear factor-kappa B and modulating intestinal apoptosis and cell proliferation. Clin Exp Immunol. 2014;178(3):537-47.

24. Chen YJ, Chen YY, Wu CT, Yu CC, Liao HF. Prolamin, a rice protein, augments anti-leukaemia immune response. J Cereal Sci. 2010;51(2):189-97.

25. Liao HF, Chen YY, Yang YC, Wang CS, Chen YJ. Rice (Oryza sativa L.) inhibits growth and induces differentiation of human leukemic U937 cells through activation of peripheral blood mononuclear cells. Food Chem Toxicol. 2006;44(10):1724-9.

26. Kubota M, Saito $Y$, Masumura T, Kumagai T, Watanabe R, Fujimura S, et al. Improvement in the in vivo digestibility of rice protein by alkali extraction is due to structural changes in prolamin/protein body-I particle. Biosci Biotechnol Biochem. 2010;74(3):614-9.

27. Ju ZY, Hettiarachchy NS, Rath N. Extraction, denaturation and hydrophobic properties of rice flour protein. J Food Sci. 2001;66(2):229-32.
28. Lee KS, Jeong ES, Heo SH, Seo JH, Jeong DG, Choi YK. A novel model for human atopic dermatitis: application of repeated DNCB patch in BALB/C mice, in comparison with NC/Nga mice. Lab Anim Res. 2010;26(1):95-102.

29. Matsuda H, Watanabe N, Geba GP, Sperl J, Tsudzuki M, Hiroi J, et al. Development of atopic dermatitis-like skin lesion with IgE hyperproduction in NC/Nga mice. Int Immunol. 1997;9(3):461-6.

30. Kim EC, Lee HS, Kim SK, Choi MS, Lee S, Han JB, et al. The bark of Betula platyphylla var. japonica inhibits the development of atopic dermatitis-like skin lesions in NC/Nga mice. J Ethnopharmacol. 2008;116(2):270-8.

31. Snapper CM, Paul WE. Interferon-gamma and B cell stimulatory factor-1. reciprocally regulate Ig isotype production. Science. 1987;236(4804):944-7.

32. Stone KD, Prussin C, Metcalfe DD. IgE, mast cells, basophils, and eosinophils. J Allergy Clin Immunol. 2010;125(25):73-80.

33. Kidd P. Th1/Th2 balance: the hypothesis, its limitations, and implications for health and disease. Altern Med Rev. 2003:8(3):223-46.

34. Amsen D, Blander JM, Lee GR, Tanigaki K, Honjo T, Flavell RA. Instruction of distinct CD4 T helper cell fates by different notch ligands on antigen-presenting cells. Cell. 2004;117(4):515-26.

35. Mazmanian SK, Liu CH, Tzianabos AO, Kasper DL. An immunomodulatory molecule of symbiotic bacteria directs maturation of the host immune system. Cell. 2005;122(1):107-18.

36. Biedermann T, Röcken M, Carballido JM. TH1 and TH2 lymphocyte development and regulation of $\mathrm{TH}$ cell-mediated immune responses of the skin. J Investig Dermatol Symp Proc. 2004;9(1):5-14

37. Wang G, Savinko T, Wolff H, Dieu-Nosjean MC, Kemeny L, Homey B, et al. Repeated epicutaneous exposures to ovalbumin progressively induce atopic dermatitis-like skin lesions in mice. Clin Exp Allergy. 2007;37(1):151-61.

38. Hänel KH, Cornelissen C, Lüscher B, Baron JM. Cytokines and the skin barrier. Int J Mol Sci. 2013;14(4):6720-45.

39. Hatano Y, Terashi H, Arakawa S, Katagiri K. Interleukin-4 suppresses the enhancement of ceramide synthesis and cutaneous permeability barrier functions induced by tumor necrosis factor-alpha and interferon-gamma in human epidermis. J Invest Dermatol. 2005;124(4):786-92.

40. Rescigno M, Rotta G, Valzasina B, Ricciardi-Castagnoli P. Dendritic cells shuttle microbes across gut epithelial monolayers. Immunobiology. 2001;204(5):572-81.

41. Mowat AM. Anatomical basis of tolerance and immunity to intestinal antigens. Nat Rev Immunol. 2003;3(4):331-41.

42. Morelli AE, Thomson AW. Dendritic cells: regulators of alloimmunity and opportunities for tolerance induction. Immunol Rev. 2003;196(1):125-46.

\section{Submit your next manuscript to BioMed Central and take full advantage of:}

- Convenient online submission

- Thorough peer review

- No space constraints or color figure charges

- Immediate publication on acceptance

- Inclusion in PubMed, CAS, Scopus and Google Scholar

- Research which is freely available for redistribution

Submit your manuscript at www.biomedcentral.com/submit 